\title{
Commentaries
}

\section{Allelic variation in Helicobacter pylori: progress but no panacea}

Helicobacter pylori colonisation in the stomach is associated with increased risk for the development of peptic ulcer disease and non-cardia gastric adenocarcinoma. ${ }^{1}$ However, the incidences of these diseases vary in different parts of the world, and these rates have been changing over the past century. It now is clear that the mere presence of $H$ pylor $i$ is insufficient to account for this variation. Alternative hypotheses to explain differing outcomes include variation in bacterial strains, in host related factors, or in the particular interactions governing the long term equilibrium between $H$ pylori strain populations and the colonised host. $^{2}$ In this issue, Kidd et al (see page 499) explore whether $H$ pylori strain differences are related to illness occurrence in South African patients undergoing endoscopy. Why was such a study undertaken?

Despite overall conservation of most genes, $H$ pylori are a highly diverse bacterial species. ${ }^{3}$ Their population structure indicates that they are freely recombining, ${ }^{4}$ which tends to eliminate clonal or allelic variation. Yet, in accordance with previous work, Kidd et al found that important clonal differences exist, even within the single geographical locale studied. Three important allelic differences are the presence or absence of the cag island, the $\mathrm{m} 1$ or $\mathrm{m} 2$ alleles of $v a c A$, and the independent $\mathrm{s} 1$ and $\mathrm{s} 2$ alleles of $v a c A^{5} ; \mathrm{s} 1$ can now be divided into s1a, s1b, and s1c. ${ }^{6}$ Although the boundaries of these alleles are not fully defined and probably shift, their very existence, against the strong pressure of the recombinational tide, indicates their important biological roles for $H$ pylori populations.

It is unlikely that the differential ability to cause disease in humans is responsible for this bacterial variation, as ulcer disease and gastric cancer chiefly occur late in life. Thus, these diseases per se are unlikely to have an important role in aiding the transmission of $H$ pylori to new hosts that is in any way analogous to the ability of Mycobacterium tuberculosis to facilitate its own transmission by causing cavitary lung disease. More likely, differential disease risk associated with particular $H$ pylori alleles is a consequence of particular bacterial adaptations that facilitate colonisation. For example, adaptation (lifestyle) differences that exist between cag+ and cag- strains now have been defined experimentally. ${ }^{7}$ It may be that the lifestyle of the colonising bacterial population reflects the summation of all the particular allelic variations. Van Doorn and colleagues have used the combination of cag, vac $A$, and ice $A$ allelic differences to provide a very rough approximation of disease risk. ${ }^{8}$

Kidd and colleagues have added to our understanding of $H$ pylori strain variation and disease in several ways. Firstly, they present evidence indicating that at least 12 (35\%) of 34 patients studied were colonised by more than a single $H$ pylori strain, which extends our understanding of the reservoir for recombination under contemporary circumstances, and further indicates that study of only a single isolate from a patient is suboptimal. Secondly, they confirm that $H$ pylori genotype distribution has geographic clustering, with a very high proportion of South African isolates being cag+ and
vacA s1b. Thirdly, they show that particular genotypes are associated with particular diseases. Their results parallel those from the United States and Europe, but the association of $\mathrm{s} 1 \mathrm{~b} / \mathrm{m} 1$ strains with gastric cancer is new. In particular, this finding emphasises that the particular associations found to date (and those not found), are human population specific. In coming years, investigators will need to categorise such associations in each major population group. For example, although the presence of cag+ $H$ pylori strains is associated with both increased ulcer and gastric cancer risk in the USA, Europe, and Latin America, their role in Asia is much more obscure, and their ubiquity in this African population indicates their insufficiency to account for disease occurrence differences. Nevertheless, compared with the absence of $H$ pylori, colonisation by s2 strains seems to have little impact on disease occurrence in this South African population, and in other groups studied. ${ }^{58}$ Fourthly, Kidd and colleagues studied size heterogeneity of the $\operatorname{cag} A$ 3' region, a new genotype in relation to disease occurrence. Their work, confirming observations in German and Japanese studies, ${ }^{9}{ }^{10}$ suggests that certain cag $A$ 3' variants may be markers of particular diseases.

However, although helpful for stratifying risk, just as $H$ pylori presence is helpful, the presently known $H$ pylori allelic differences are insufficient to explain fully variation in disease occurrence, and do not sufficiently account for geographical variation or temporal changes in disease rates. Rather, the key to understanding $H$ pylori related diseases is likely to be the interaction term between host genotype, host environment, and gastric microbial populations. I have hypothesised ${ }^{11}$ that the age at which $H$ pylori is acquired, and the multiplicity of different organisms colonising the stomach have important bearing on gastric microecology, and thus, ultimately, on disease risk. Nevertheless, those looking for simple answers about the relations of $H$ pylori and disease undoubtedly will be disappointed; the complexity likely is older than the human race. However, the challenge is great, and the clinic is our laboratory. Clinical researchers, microbiologists, experimental pathologists, and mathematicians each can contribute to solving the puzzle.

Conflict of interest: $\mathrm{M} \mathrm{J}$ Blaser holds patents relating to $H$ pylori genotypes, serology, and vaccines.

M J BLASER

Division of Infectious Diseases,

Vanderbilt University School of Medicine and

Department of Veterans Affairs Medical Centre,

A-3310 Medical Centre North,

Nashville, TN 37232-2605, USA

email:martin.blaser@mcmail.vanderbilt.edu

1 Blaser MJ. The changing relationships of Helicobacter pylori and humans: implications for health and disease. F Infect Dis 1999;179:1523-300.

2 Blaser MJ, Kirschner D. Dynamics of Helicobacter pylori colonization in relation to the host response. Proc Natl Acad Sci USA 1999;96:8359-64.

3 Go MF, Kapur V, Graham DY, et al. Population genetic analysis of Helicobacter pylori by multilocus enzyme electrophoresis: extensive allelic diversity and recombinational population structure. F Bacteriol 1996;178:3934-

4 Suerbaum S, Maynard Smith J, Bapumia K, et al. Free recombination within Helicobacter pylori. Proc Nat Acad Sci USA 1998;95:12619-24.

5 Atherton J, Cao P, Peek RM, et al. Mosaicism in vacuolating cytotoxin alleles of Helicobacter pylori: association of specific vacA types with cytotoxin of Helicobacter pylori: association of specific vacA types with cy
production and peptic ulceration. F Biol Chem 1995;270:17771-7.

6 van Doorn L-J, Figueirdo C, Megraud F, et al. Geographic distribution of 6 van Doorn L-J, Figueirdo C, Megraud F, et al. Geographic distribution of

7 Blaser MJ. The interaction of cag ${ }^{+}$Helicobacter pylori strains with their hosts. In: Hunt RH, Tytgat GNJ, eds. Helicobacter pylori, basic mechanisms to hosts. In: Hunt RH, Tytgat GNJ, eds. Helicobact
clinical cure. Dordrecht: Kluwer, 1998:27-32. 
8 Van Doorn L, Figueiredo C, Sanna R, et al. Clinical relevance of the cagA, vacA and iceA status of Helicobacter pylori. Gastroenterology 1998;115:58-66. Rudi J, Kolb C, Maiwald M, et al. Diversity of Helicobacter pylori vacA and cagA genes and relationship to VacA and CagA protein expression, cytotoxin production and associated diseases. F Clin Microbiol 1998;36: $944-8$.
10 Yamaoka Y, Kodama T, Kashima K, et al. Variants of the 3' region of the cagA gene in Helicobacter pylori isolates from patients with different $\mathrm{H}$. cagA gene in Helicobacter pylori isolates from patients with

11 Blaser MJ. Helicobacters are indigenous to the human stomach: duodenal ulceration is due to changes in gastric microecology in the modern era. Gut 1998;43:721-7.

\section{Short bowel, short answer?}

The paper by Jeppsen et al (see page 559) shows that glucagon-like peptide-2 (GLP-2) concentrations are low in patients lacking an ileum and colon. This is not an unexpected finding as the L cells that produce GLP-2 are situated in the ileum and colon. GLP-2 is an enterocyte specific growth hormone that in mice causes small and large bowel villus/crypt growth and increases small and large bowel length and weight. In mice it also reduces body weight loss and restores mucosal integrity after dextran induced colitis. In pigs it reduces gastric antral motility. ${ }^{1}$ The deficiency of GLP-2 in patients with a jejunostomy may explain why these patients show no evidence of structural or functional intestinal adaptation over time. ${ }^{2-4}$

A distal ileal/colonic peptide with glucagon-like immunoreactivity has been recognised for many years and termed enteroglucagon. However, the molecular structure of enteroglucagon was originally unknown and serum concentrations were derived by subtracting pancreatic glucagon concentrations from total glucagon-like immunoreactivity. ${ }^{5}$ Enteroglucagon producing tumours were associated with mucosal hyperplasia ${ }^{67}$ and enteroglucagon was thought to be responsible for the ileal adaptation that occurred after a jejunal resection. GLP-2 is likely to be the most important mucosal growth stimulating hormone. ${ }^{8}$ Its consists of 33 amino acids and its structure is highly conserved throughout all mammalian species (only one amino acid different in the rat). It has been synthesised and its receptor characterised. ${ }^{1}$ As it stimulates mucosal growth there is the possibility of giving it to patients with a short bowel to promote adaptation, or to adults or children with intestinal damage (e.g. from ischaemia, irradiation, chemotherapy, severe coeliac disease, necrotising enterocolitis or congenital microvillus atrophy).

When the jejunum is resected, the remaining ileum undergoes both structural and functional adaptation. Structural adaptation is apparent as the bowel increases in width, its villi become longer and crypts deeper. Functional adaptation is shown by measuring increases (with time or compared with normal subjects) in the absorption of macro- and/or micronutrients over a given length of bowel. Functional adaptation may be the result of structural changes, a slowing of transit rate or intracellular molecular events (e.g. increased transport and/or enzyme activity). ${ }^{9}$ Patients with a short bowel commonly encountered in clinical practice do not have a retained ileum; they have either a jejuno-colic anastomosis or a jejunostomy. ${ }^{3}$ There is no convincing evidence in humans that the remaining jejunal mucosa can adapt structurally in either of these situations ${ }^{410}$; however, patients with a retained colon do show evidence of function adaptation. ${ }^{11-13}$

The clinical problems experienced by the two types of patient with a short bowel are different. Both have problems with nutrient absorption; however, patients with a jejunostomy also lose large amounts of water and sodium from their stoma. ${ }^{14}$ This is because of loss of normal daily intestinal secretions (about 4 litres/24 hours), rapid gastric emptying and rapid small bowel transit. ${ }^{15}$ If a patient has less than $100 \mathrm{~cm}$ jejunum remaining and a stoma he/she is likely, as a minimum, to need long term parenteral saline. ${ }^{14}$ This requirement does not reduce with time. ${ }^{3}$ Patients with a retained colon do not have these problems and, owing to functional adaptation, nutrient absorption usually improves with time. To explain the differences between the two types of patient, measurements of various gastrointestinal hormones have been made with interest focusing upon those produced by the ileum and colon. Peptide YY, which like GLP-2 is produced by the L cells of the ileum and colon, slows gastric emptying and small bowel transit and may be responsible for the "ileal" and "colonic" brakes. Peptide YY serum values are high in patients with a retained colon and low in patients with a jejunostomy. ${ }^{16}$ Thus peptide YY may be responsible for part of the functional adaptation that occurs in patients with a retained colon; however, it is unlikely to induce structural changes. ${ }^{17}$

Data are not yet available about GLP-2 values in patients with a jejuno-colic anastomosis. If high, this may represent an adaptive mechanism by which GLP-2 increases intestinal growth and slows gastric emptying. Thus GLP-2 serum values could become a useful measure of the amount of intestinal adaptation. If GLP-2 values are low, then it will be important to study the therapeutic effects of administering it. There may even be a congenital defect in absorption related to a deficiency of GLP-2.

The importance of GLP-2 is just starting to be recognised. Its role in promoting intestinal growth makes it a potentially useful treatment for patients with a short or damaged bowel. The role of GLP-2 (and peptide YY) in inducing jejunal structural and functional adaptation will only become clearer after they (or analogues) have been infused/injected into patients with a short bowel, and the short and long term effects documented.

Department of Gastroenterology,

J NIGHTINGALE

Leicester Royal Infirmary,

Leicester LE1 5WW, UK

Druker DJ. Glucagon-like peptide 2. Trends in Endocrinology and Metabolism 1999;10:153-6.

2 Hill GL, Mair WSJ, Goligher JC. Impairment of 'ileostomy adaptation' in patients after ileal resection. Gut 1974;15:982-7.

3 Nightingale JMD, Lennard-Jones JE, Gertner DJ, et al. Colonic preservation reduces the need for parenteral therapy, increases the incidence of renal stones but does not change the high prevalence of gallstones in patients with a short bowel. Gut 1992;33:1493-7.

4 O'Keefe SJD, Haymond MW, Bennet WM, et al. Long-acting somatostatin analogue therapy and protein metabolism in patients with jejunostomies. Gastroenterology 1994;107:379-88.

5 Bloom SR, Long RG. Radioimmunoassay of gut regulatory peptides. London: WB Saunders, 1982

6 Gleeson $\mathrm{MH}$, Bloom SR, Polak JM, et al. Endocrine tumour in kidney affecting small bowel structure, motility, and absorptive function. Gut 1971;12:773-82

7 Stevens FM, Flanagan RW, O'Gorman D, et al. Glucagonoma syndrome demonstrating giant duodenal villi. Gut 1984;25:784-91.

8 Dunphy JL, Fuller PJ. Enteroglucagon, bowel growth and GLP-2. Mol Cell Endocrinol 1997;132:7-11.

9 Williamson RCN, Chir M. Intestinal Adaptation. $N$ Engl $f$ Med 1978;298:1393-402; 1444-50. 
10 De Francesco A, Malfi G, Delsedime L, et al. Histological findings regarding jejunal mucosa in short bowel syndrome. Transplant Proc 1994;26:1455-6. Dowling RH, Booth CC. Functional compensation after small bowel resection in man: Demonstration by direct measurement. Lancet resection in mat

12 Gouttebel MC, Saint Aubert B, Colette C, et al. Intestinal adaptation in patients with short bowel syndrome. Measurement by calcium absorption. Dig Dis Sci 1989;34:709-15.

13 Cosnes J, Carbonnel F, Beaugerie L, et al. Functional adaptation after extensive small bowel resection in humans. Eur 7 Gastroenterol Hepatol 1994;6:197-202.
14 Nightingale JMD, Lennard-Jones JE, Walker ER, et al. Jejunal efflux in short bowel syndrome. Lancet 1990;336:765-8.

15 Nightingale JMD, Kamm MA, van der Sijp JRM, et al. Disturbed gastric emptying in the short bowel syndrome. Evidence for a "colonic brake". Gut 1993;34:1171-6.

16 Nightingale JMD, Kamm MA, van der Sijp JRM, et al. Gastrointestinal hormones in the short bowel syndrome. PYY may be the 'colonic brake' to gastric emptying. Gut 1996;39:267-72.

17 Savage AP, Gornacz GE, Adrian TE, et al. Is raised plasma peptide YY after intestinal resection in the rat responsible for the trophic response? Gut $1985 ; 26: 1353-8$

\section{Pseudo-obstruction in children: transplant or wait?}

With advances in immunosuppression intestinal transplantation has emerged as a viable option for patients with chronic intestinal failure and life threatening complications. With a one year graft survival rate of around $60 \%$ over the past few years, the current situation compares favourably with the pre-1990 results when $30 \%$ survival rates were achieved (data from the Intestinal Transplant Registry: www.lhsc.on.ca/itr). At the 7 th Meeting of the European Intestinal Transplantation Study Group (Brussels, 1998), one year survival rates up to $80-90 \%$ were reported by some very experienced centres.

In children, chronic intestinal pseudo-obstruction is often a primary disorder, either congenital or acquired. Secondary pseudo-obstruction is related to various systemic diseases and is more common in older patients. According to the pathological findings, the primary disease is classified as neuropathic, myopathic, or idiopathic if no specific pattern is recognised. The disease always involves the small bowel and may occur in any other (or all) regions of the digestive tract. Signs and symptoms of obstruction, but without anatomical obstruction being evident on conventional imaging, dominate the clinical picture. The first symptoms may appear as early as the neonatal period or later in life and range from occlusion and complete intolerance to food to recurrent abdominal pain and constipation. Chronic bacterial intestinal overgrowth and chronic central venous access for parenteral nutrition can be associated with infectious episodes, which in turn can result in evolution towards liver fibrosis/cirrhosis and cholestasis. ${ }^{12}$ Little has been reported on the long term outcome of children with primary intestinal pseudo-obstruction, especially those presenting with severe disease early in life. Because the disease is uncommon and because it usually progress slowly, the poor long term prognosis has probably been underestimated in the past.

Sigurdsson et al's experience with 27 young patients (1-19 years old) (see page 570) is of major importance for several reasons. As the patients were referred for transplant, this group is probably not representative of the general population but confirms, however, that severe complications can occur during childhood. Multidisciplinary, perioperative management is mandatory and surgery must be tailored to each individual because the disease can affect other portions of the digestive system and other organ systems. ${ }^{1}$ With expert care, good results can be achieved in this difficult group of patients, as illustrated in this series.

Of more concern is that of the 22 patients registered for transplantation, eight were transplanted, eight died before a graft became available and six were still awaiting transplant.
This is of course a result of the current shortage of donors but also reflects the poor clinical condition of the patients at the time of registration. Poor clinical condition and pre-existing complications are clearly related to an increased risk of death..$^{3-5}$ Moreover, worsening of the clinical condition while on the waiting list leads to increased post-transplant morbidity and a higher death rate..$^{3-5}$

Taking into account that the long term results of transplants are still not as good as those for long term parenteral nutrition, the timing of referral and the criteria for small bowel transplantation continue to be debated. The current general indication for bowel replacement is still the development of life threatening problems in the context of gut failure (mostly progressive liver disease and/or central venous access problems). Sigurdsson et al propose a reasonable approach-patients who do not present with cholestasis or hepatic dysfunction should be managed conservatively. These patients should benefit from the best appropriate care, minimising the risk of progressive liver disease and preventing line infections. ${ }^{6}$ This strategy adheres to the current consensus guidelines: transplantation should be avoid by adequate medical management but patients who develop complications (cholestasis, portal hypertension, vascular access problems) should be referred for transplantation.

Earlier referral and thus registration of patients while still in reasonable health may help to decrease both pre- and post-transplant risks. In a recent study, early referral for liver transplantation led to better results which in turn had a positive effect on patient selection.?

Bueno et al reported that a bilirubin concentration above $3 \mathrm{mg} / \mathrm{l}$, a prothrombin time of more than 15 seconds or bridging fibrosis at liver biopsy were significantly related to poor outcome. ${ }^{3}$ Also, $80 \%$ of the children under 1 year of age when referred for transplant assessment died within two years. $^{3}$ Thus, patients should be referred to transplant centres as early as possible before liver dysfunction or portal hypertension has developed, or at least before complications occur. Then, after a full evaluation of the patient's condition, the appropriate management strategy should be discussed with the referring team, including the option for possible future transplantation and its ideal timing.

Early referral and early interactive management between local and transplant centres is essential if the general outcome of patients in potential need of bowel replacement is to be improved.

J DE VILLE DE GOYET

Liver Unit,

Birmingham Children's Hospital,

Steelhouse Lane,

Birmingham B4 6NH, UK

1 Kocoshis S, Reyes J, Todo S, et al. Small intestinal transplantation for irreversible intestinal failure in children. Dig Dis Sci 1997;42:1997-2008.

2 Rudolph CD, Hyman PE, Altschuler SM, et al. Diagnosis and treatment of chronic intestinal pseudo-obstruction in children: report of consensus workshop. F Pediatr Gastroenterol Nutr 1997;24:102-12. 
3 Bueno J, Ohwada S, Kocoshis S, et al. Factors impacting the survival of children with intestinal failure referred for intestinal transplantation. $f$ Pediatr Surg 1999;34:27-33.

4 Langnas AN, Dhawan A, Antoson DL. Intestinal transplantation in children. Transplant Proc 1996;28:2752.

5 Goulet O. Recent studies on small intestinal transplantation. Curr Opin Gastroenterol 1997;13:500-9.
6 Moukarzel AA, Haddad I, Ament ME, et al. 230 patient years of experience with home long-term parenteral nutrition in childhood: natural history and life of central venous catheter. $f$ Pediatr Surg 199, $29.1323-7$

7 de Ville de Goyet J, Hausleithner V, Reding R, et al. Impact of innovative techniques on the waiting list and results in pediatric liver transplantation. Transplantation 1993;56:1130-6.

\section{Screening for colorectal cancer: the heart of the matter}

All screening interventions have the potential to do harm and screening by faecal occult blood testing (FOBT) is no exception. The harm arises not from the test itself, although the psychological impact is not negligible, but mainly from the investigation and treatment of test positives. The benefits of FOBT have been studied extensively and it seems that among those who comply with biennial testing, colorectal cancer mortality is significantly reduced $^{1-3}$ and that the reduction is greater when the test is used annually. ${ }^{4}$ But there is a price to pay. Firstly, there is the anxiety engendered by performing the test itself and the greater anxiety induced in those who are found to be positive requiring further investigation. Although this has been shown to be short-lived, lasting mainly until the completion of diagnostic investigations, cumulatively it might be expected to affect around $10 \%$ of those complying with the test biennially over 20 years.

Secondly, there are the well documented complications associated with colonoscopy, which is considered the gold standard for the diagnostic workup of test positives. ${ }^{5}$ Overall mortality rates are reported to average around $0.02 \%$, varying between 0 and $0.06 \%$. Perforation can be expected in $0.3 \%$ and haemorrhage in around $1 \%$ of people undergoing polypectomy. A variety of other complications have been reported, the most serious of which are cardiovascular. ${ }^{6}$ Finally, there is the significant morbidity associated with the surgical treatment of colorectal cancer and large adenomas, with published 30-day mortality rates varying between 1 and $8 \%{ }^{7}$

Based on the promising findings of the randomised trials, pilot studies of FOBT screening are about to start in two sites in the UK in preparation for possible implementation in a national screening programme. These studies aim to examine feasibility and acceptability rather than efficacy and adverse effects. Therefore the paper in this issue reporting on the adverse effects of screening in the Nottingham study is timely. Robinson et al (see page 588) specifically tackle three issues raised by Ahlquist ${ }^{6}$ in a paper questioning the wisdom of implementing screening by FOBT. Ahlquist argues: (1) that false negative results falsely reassure patients, leading to delayed diagnosis and poorer outcome; (2) that colonoscopic mortality compounded over several years could counter any gains in reducing deaths from colorectal cancer; (3) that true positive FOBT results may lead to overdiagnosis and treatment of asymptomatic colorectal cancers which might have an innocuous natural history, perhaps leading to a shortened lifespan. To counter the first point, Robinson et al show that there is no difference in the stage at diagnosis in interval and control cancers, suggesting that false negative FOBTs probably do not delay diagnosis. In response to the second point, they show that there were no colonoscopy deaths although their perforation rate ( 5 of $1474,0.3 \%$ ) was exactly as that reported by Ahlquist. Moreover, they restrict their analysis only to baseline colonoscopies even though those who were found to have adenomas were entered into a colonoscopic surveillance programme. If we assume that the $40 \%$ of patients undergoing colonoscopy who were found to have adenomas underwent an average of two more colonoscopies, this approximately doubles the exposure of the cohort to colonoscopy.

One point not tackled by Robinson et al was the observation by Ahlquist that, in the Minnesota study, ${ }^{4}$ the reduction in colorectal mortality was precisely offset by an increase in mortality from cardiac ischaemia. An increase in cardiovascular deaths, of similar magnitude to the reduction in colorectal cancer mortality, was also observed in the Danish study. ${ }^{2}$ The non-colorectal cancer mortality rate was also increased in Nottingham, ${ }^{1}$ more than offsetting any reduction in deaths from colorectal cancer, therefore it would have been of interest to have examined deaths from ischaemic heart disease in Nottingham (table 1).

Table 1 Proportion of deaths due to various causes by screening arm in randomised trials of faecal occult blood testing

\begin{tabular}{|c|c|c|c|c|c|c|}
\hline & \multicolumn{2}{|c|}{ Screened } & \multicolumn{2}{|l|}{ Control } & \multicolumn{2}{|c|}{ Screened $<$ Control } \\
\hline & $n$ & $\%$ & $n$ & $\%$ & Difference (n) & Difference (\%) \\
\hline Hardcastle and colleagues $^{1}$ & 75253 & & 74998 & & & \\
\hline All causes & 12624 & 16.78 & 12515 & 16.69 & +109 & +0.09 \\
\hline CRC & 360 & 0.48 & 420 & 0.56 & -60 & -0.08 \\
\hline $\begin{array}{l}\text { Non-CRC } \\
\text { IHD }\end{array}$ & 12264 & 16.30 & 12095 & 16.13 & +169 & +0.17 \\
\hline Kronborg and colleagues $^{2}$ & 30967 & & 30966 & & & \\
\hline All causes & 6228 & 20.11 & 6303 & 20.35 & -75 & -0.24 \\
\hline CRC & 182 & 0.59 & 230 & 0.74 & -48 & -0.16 \\
\hline Non-CRC & 6046 & 19.52 & 6073 & 19.61 & -27 & -0.09 \\
\hline Cardiovascular & 2497 & 8.06 & 2443 & 7.89 & +54 & +0.17 \\
\hline Mandel and colleagues ${ }^{4}$ & 15570 & & 15394 & & & \\
\hline All causes & 3361 & 21.59 & 3340 & 21.70 & +21 & -0.11 \\
\hline CRC & 82 & 0.53 & 121 & 0.79 & -39 & -0.26 \\
\hline Non-CRC & 3279 & 21.06 & 3219 & 20.91 & +60 & +0.15 \\
\hline IHD & 1079 & 6.93 & 1025 & 6.66 & +54 & +0.27 \\
\hline
\end{tabular}

CRC, colorectal cancer; IHD, ischaemic heart disease. 
So what should we make of this? If there is an increase in deaths from coronaries, when do they occur and what is causing them? Robinson et al state that none of 1778 patients who were not being treated for detected colorectal neoplasia, died within 30 days of colonic investigation. It is not clear how many suffered a cardiac event within that time which might have led to death at a later time. Myocardial infarction during colonoscopy seems to be rare $^{5}$ with a large US survey reporting three $(0.012 \%)$ events in 25298 colonoscopies, but the incidence of infarction within a few hours or days of colonoscopy is unknown.

The possibility of an increase in coronary mortality observed in the published randomised trials of colorectal screening suggests that lower gastrointestinal endoscopy and surgery should be undertaken judiciously, balancing in each patient the risks and benefits. Haemoccult, the FOBT used in the European randomised trials, when used in the unrehydrated form is a specific test with a predictive value for cancer of a positive test of around $10 \%$. There is no other indication for colonoscopy in which the yield of cancers is so high. However around $40 \%$ of those undergoing colonoscopy as a result of a positive FOBT are found to have adenomas and it is customary to enter them into an endoscopic surveillance programme where the benefits are less clearly defined and, perhaps more importantly, the harm has yet to be quantified.

ICRF Colorectal Cancer Unit,

W S ATKIN

St Mark's Hospital,

Northwick Park,

Watford Road,

Harrow,

Middlesex HA1 3Uf, UK

1 Hardcastle J, Chamberlain J, Robinson $M$, et al. Randomised controlled trial of faecal-occult-blood screening for colorectal cancer. Lancet 1996; 348:1472-7.

2 Kronborg O, Fenger C, Olsen J, et al. Randomised study of screening for colorectal cancer with faecal-occult-blood test. Lancet 1996;348:1467-71.

3 Mandel J, Church T, Ederer F, et al. Colorectal cancer mortality: effectiveness of biennial screening for fecal occult blood. I Natl Cancer Inst 1999;91: 434-7.

4 Mandel J, Bond J, Church T, et al. Reducing mortality from colorectal cancer by screening for fecal occult blood. N Engl f Med 1993;328:1365-71.

5 Waye J, Kahn O, Auerbach M. Complications of colonoscopy and flexible sigmoidoscopy. Gastrointest Endosc Clin North Am 1996;6:343-77.

6 Ahlquist DA. Fecal occult blood testing for colorectal-cancer-can we afford to do this. Gastroenterol Clin North Am 1997;26:41-55.

7 Royal College of Surgeons of England and Association of Coloproctology of Great Britain and Ireland. Guidelines for the management of colorectal cancer. London: Royal College of Surgeons of England and Association of Coloproctology of Great Britain and Ireland, 1996.

\section{HCV in hepatic failure: West and East do not meet}

Despite the identification of hepatitis $\mathrm{C}$ virus $(\mathrm{HCV})$ as an aetiological agent of blood borne non-A, non-B (NANB) hepatitis a decade ago, its role in fulminant NANB hepatitis is still uncertain. ${ }^{1}$ In the West, $\mathrm{HCV}$ is only infrequently associated with NANB fulminant hepatitis. Thus, in studies from the USA, positive serum HCV RNA was reported in none of 15 cases by Wright and colleagues $^{2}$ and in only two (12\%) of 17 cases by Liang et al. ${ }^{3}$ Similarly, none of the 23 and 30 NANB cases in the French and English series, respectively, was positive for $\mathrm{HCV}$ infection. ${ }^{45}$ In contrast, the prevalence of serological markers of $\mathrm{HCV}$ infection in NANB fulminant hepatitis is much higher in the Oriental countries. In an early study from Japan, Muto et al found that seven (58\%) of 12 patients with NANB fulminant hepatitis were anti-HCV (anti-C100-3) positive $^{6}$; findings which were later confirmed by Yangi et al who reported detectable serum $\mathrm{HCV}$ RNA in $43 \%$ (3/7) of cases of NANB fulminant hepatitis. ${ }^{7}$ In Taiwan-geographically close to Japan-HCV RNA was detected in $45-50 \%$ of patients with NANB fulminant hepatitis $^{89}$ and in the Republic of China, more than $50 \%$ of patients with various types of fulminant viral hepatitis had anti-HCV. ${ }^{10}$

The cause of this discrepancy between findings in the West and East is uncertain. Views of the pathogenesis of fulminant viral hepatitis suggest that an aggressive early host immune response to the virus is the cause of massive hepatocellular necrosis. Levels of the causative virus in the serum and liver may be high before the "peak" of liver damage and due to immune clearance, the viral load could be below the detection limit of currently available assays when the patients are first seen at the time of severe liver damage.${ }^{11}$ Hence, in the absence of serial serum samples, in particular those preceding the patient's admission to hospital, early HCV viraemia may have been missed. In many series the diagnosis has been based on the presence of anti-HCV rather than HCV RNA in the serum and unlike HCV RNA, anti-HCV is usually not detectable for two to three months after the initial exposure and infection. With the short time course of illness, patients with fulminant hepatic failure may not survive long enough to develop detectable anti-HCV in the serum. In most of the studies tackling the issue of HCV aetiology in NANB fulminant hepatitis, serial serum samples during and after the illness are lacking. However, in a recent study by an NIH group, the level of HCV viraemia, as measured by branched-chain DNA assay, increased in parallel with serum alanine aminotransferase concentrations and the degree of hepatocellular necrosis, indicative perhaps of a direct cytopathic effect of the virus. ${ }^{12}$ Accordingly, a single negative test for HCV RNA, by PCR, in a patient with fulminant hepatitis would rule out $\mathrm{HCV}$ as the cause. This finding certainly requires further validation.

As the various $\mathrm{HCV}$ genotypes have geographical preferences: $1 \mathrm{~b}$ in Oriental countries and $1 \mathrm{a}$ in the USA, another possibility would be that the differences between East and West in fulminant NANB hepatitis are related to distinct HCV genotypes. This possibility was explored in the prospective study reported in this issue by $\mathrm{Chu}$ et al (see page 613). One hundred and nine consecutive HCV RNA positive patients with acute hepatitis admitted to a Taiwan hospital were investigated. Eleven patients $(10.1 \%)$ developed fulminant hepatic failure but no correlation could be detected between the occurrence of fulminant hepatitis and HCV genotype. Other viral factors such as HCV viral load and coinfection with hepatitis $G$ virus (HGV) were also investigated and were not found to be related to the occurrence of a fulminant course. One shortcoming was the lack of cases with genotype $1 \mathrm{a}$ in the current series which could have weakened the significance of the findings. In a recent human-to-chimpanzee transmission experiment, the same HCV strain, genotype 
1a, which had been associated with two episodes of fulminant hepatic failure in a single patient, caused severe hepatitis in the chimpanzee. This suggested that genotype $1 \mathrm{a}$ - as most frequently found in the USA - can be directly related to the occurrence of severe liver damage. ${ }^{13}$

One important finding in the study by Chu et al was the presence of concomitant chronic hepatitis B virus (HBV) infection, as defined by positive HBV surface (HBsAg) and negative IgM anti-HBV core ( $\mathrm{HBc}$ ) antigens in nine $(82 \%)$ of 11 subjects who developed fulminant hepatic failure compared with only $30 / 98(31 \%)$ of those with non-fulminant acute HCV hepatitis $(\mathrm{p}<0.05)$. This is in keeping with a study from France which showed that eight $(47 \%)$ of $17 \mathrm{HBsAg}$ positive patients with fulminant hepatic failure were also HCV RNA positive, although on no occasion in that series was $\mathrm{HCV}$ infection alone demonstrable. Furthermore, Wright et al detected HBV DNA by PCR in the liver specimen from six of 12 patients with "NANB" fulminant hepatic failure treated by transplantation who had negative HBV serological markers and undetectable serum HBV DNA in the serum by PCR. ${ }^{2}$ It has also been shown that acute hepatitis $\mathrm{C}$ infection in patients with chronic HBV can suppress markers of $\mathrm{HBV}$ infection and even displace HBsAg from serum. ${ }^{14}{ }^{15}$ Hence, in some instances of $\mathrm{HCV}$ superinfection of $\mathrm{HBV}$ carriers or concomitant dual infection, HBV serological markers may not be detectable and the severe liver damage may be attributed to $\mathrm{HCV}$ alone. It is also possible that without the co-factor of $\mathrm{HBV}$ infection-much more likely in areas of high prevalence as in the East- $\mathrm{HCV}$ will less frequently be the cause of fulminant hepatic failure. Whatever the inter-relation between HCV and HBV infection in the East, it is clear that in the West there is still a significant percentage of cases of fulminant hepatic failure from presumed viral hepatitis where no markers of hepatitis viral infection can currently be identified.

GEORGE K K LAU ROGER WILLIAMS

Institute of Hepatology,

University College London,

69-75 Chenies Mews,

London WC1E 6HX, UK

Correspondence to: Professor Williams.

1 Lidofsky SD. Fulminant hepatic failure. Crit Care Clin 1995;11:415-30.

2 Wright TL, Mamish D, Combs C, et al. Hepatitis B virus and apparent fulminant non-A, non-B hepatitis. Lancet 1992;339:952-5.

3 Liang TJ, Jeffers L, Reddy RK, et al. Fulminant or subfulminant non-A, non-B viral hepatitis: the role of hepatitis $\mathrm{C}$ and $\mathrm{E}$ viruses. Gastroenterology 1993;104:556-62.

4 Feray C, Gigou M, Samuel D, et al. Hepatitis C virus RNA and hepatitis B virus DNA in serum and liver of patients with fulminant hepatitis. Gastroenterology 1993;104:549-55.

5 Sallie R, Silva AE, Purdy M, et al. Hepatitis C and E in non-A non-B fulminant hepatic failure: a polymerase chain reaction and serological study. $\mathcal{F}$ Hepatol 1994;20:580-8.

6 Muto Y, Sugihara J, Ohnishi H, et al. Anti-hepatitis C virus antibody prevails in fulminant hepatic failure. Gastroenterol $\mathcal{F}_{p} n$ 1990;25:32-5.

7 Yanagi $\mathrm{M}$, Kaneko S, Unoura $\mathrm{M}$, et al. Hepatitis $\mathrm{C}$ virus in fulminant hepatic failure. N Engl f Med 1991;324:1895-6.

8 Chu CM, Sheen IS, Liaw YF. The role of hepatitis C virus in fulminant viral hepatitis in an area with endemic hepatitis A and B. Gastroenterology 1994; hepatitis in $189-95$.

9 Wu JC, Chen CL, Hou MC, et al. Multiple viral infection as the most common cause of fulminant and subfulminant viral hepatitis in an area endemic for hepatitis B: Application and limitations of the polymerase chain reaction. Hepatology 1994;19:836-40.

10 Zhao YR, Zhang DF, Pan CQ. An etiological study on fulminant viral hepatitis. Chin F Int Med 1992;31:686-8.

11 Lugassy C, Bernuau J, Thiers V, et al. Sequences of hepatitis B virus DNA in the serum and liver of patients with acute benign and fulminant hepatitis. F Infect Dis 1987;155:64-71

12 Farci P, Alter HJ, Shimoda A, et al. Hepatitis C virus-associated fulminant hepatic failure. $N$ Engl F Med 1996;335:631-4

13 Farci P, Munoz SJ, Shimoda A, et al. Experimental transmission of hepatitis C virus-associated fulminant hepatitis to a chimpanzee. I Infect Dis 1999:179:1007-11.

14 Liaw YF, Tsai SL, Chang JJ, et al. Displacement of hepatitis B virus by hepatitis $\mathrm{C}$ virus as the cause of continuing chronic hepatitis. Gastroenterology 1994 106:1048-53.

15 Lau GKK, Wu PC, Lo CK, et al. Histological changes of concurrent hepatitis $\mathrm{C}$ virus infection in asymptomatic hepatitis B virus patients. $\mathcal{F}$ Gastroenterol Hepatol 1998;13:52-6. 